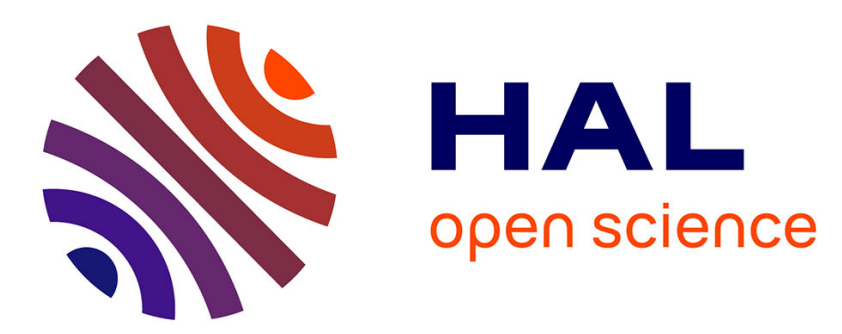

\title{
IOPE: Interactive Ontology Population and Enrichment Guided by Ontological Constraints
}

Shadi Baghernezhad-Tabasi, Loïc Druette, Fabrice Jouanot, Celine Meurger, Marie-Christine Rousset

\section{- To cite this version:}

Shadi Baghernezhad-Tabasi, Loïc Druette, Fabrice Jouanot, Celine Meurger, Marie-Christine Rousset. IOPE: Interactive Ontology Population and Enrichment Guided by Ontological Constraints. 37eme Conférence sur la Gestion de Données - Principes, Technologies et Applications (BDA 2021, Oct 2021, Paris, France. hal-03448134

\section{HAL Id: hal-03448134 \\ https://hal.science/hal-03448134}

Submitted on 25 Nov 2021

HAL is a multi-disciplinary open access archive for the deposit and dissemination of scientific research documents, whether they are published or not. The documents may come from teaching and research institutions in France or abroad, or from public or private research centers.
L'archive ouverte pluridisciplinaire $\mathbf{H A L}$, est destinée au dépôt et à la diffusion de documents scientifiques de niveau recherche, publiés ou non, émanant des établissements d'enseignement et de recherche français ou étrangers, des laboratoires publics ou privés. 


\title{
IOPE: Interactive Ontology Population and Enrichment Guided by Ontological Constraints
}

\author{
Shadi Baghernezhad-Tabasi ${ }^{1}$, Loïc Druette ${ }^{2}$, Fabrice Jouanot ${ }^{1}$, \\ Celine Meurger ${ }^{2}$, Marie-Christine Rousset ${ }^{1,3}$ \\ ${ }^{1}$ Université Grenoble Alpes, CNRS, LIG, Grenoble, France, ${ }^{2}$ Université Claude Bernard Lyon 1, SAMSEI, Lyon, France, \\ ${ }^{3}$ Institut Universitaire de France, Paris, France \\ ${ }^{1}$ firstname.lastname@univ-grenoble-alpes.fr, ${ }^{2}$ firstname.lastname@univ-lyon1.fr
}

\begin{abstract}
In this paper, we focus on the construction of specialized ontologies that capture skills of experienced experts in a particular domain with the goal of sharing them with a larger community of trainees or less experienced experts in the domain. Our main contribution is the automatic construction of a Graphical User Interface (GUI) named IOPE built from the ontological constraints of an input ontology, as the support for the controlled update process of the considered ontology. The resulting GUI functions as a guidance for the experts with no knowledge of OWL/RDFS, which enables them to easily explore and update their ontologies. We illustrate the functionality of IOPE on an ontology for simulation-based medical workshops called OntoSAMSEI.
\end{abstract}

\section{INTRODUCTION}

Ontologies are the backbone of many information systems that require access to structured knowledge. By their very nature, realworld ontologies are dynamic artifacts that evolve both in their structure (the data model) and their content (instances). Keeping them up-to-date is a critical operation for most applications which rely on semantic Web technologies. Ontology updates encompass both enrichment and population. Ontology updates are often performed manually, as the non-documented knowledge of the domain expert is required to be taken into consideration. However, this manual updates put burden on the experts and render the whole ontological ecosystem inefficient. In this paper, we advocate for an alternative and more effective approach, and propose to handle updates automatically through a few interactions with the expert, using a Graphical User Interface (GUI).

The challenges associated to interaction-based automatic updates are two-fold: ( $i$ ) While ontologies are typically represented in the form of graphs, it is inherently difficult and counter-intuitive to provide a graphical graph-based representation of ontologies for the consumption of experts. While there exist several methods to visualize a graph structure $[1,2]$, the outcome is often hard to digest by domain experts. (ii) It is unclear how experts should perform ontology updates through the interactions, without the prior knowledge of the formal syntax and the semantics of ontology languages.

(C) 2021, Copyright is with the authors. Published in the Proceedings of the BDA 2021 Conference (October 25-28, 2021, En ligne, France). Distribution of this paper is permitted under the terms of the Creative Commons license CC-by-nc-nd 4.0.

(C) 2021, Droits restant aux auteurs. Publié dans les actes de la conférence BDA 2021 (25-28 octobre 2021, En ligne, France). Redistribution de cet article autorisée selon les termes de la licence Creative Commons CC-by-nc-nd 4.0.

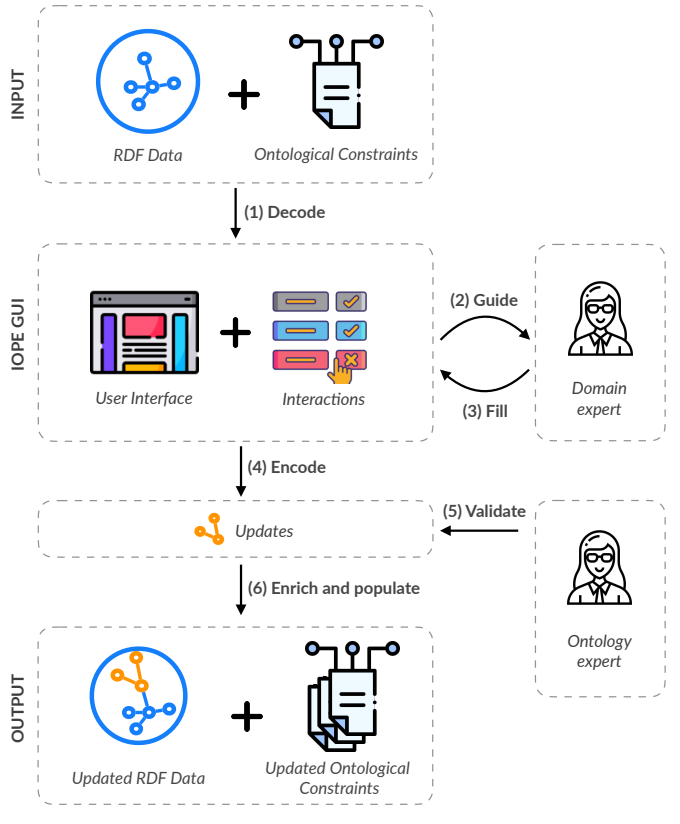

Figure 1: Overview of IOPE workflow

In this paper, we demonstrate IOPE (Interactive Ontology Population and Enrichment), a framework for the automatic construction of a GUI using prefilled Web forms. We leverage Web forms as a natural interaction means to tackle the challenge of counterintuitive ontology representations. IOPE generates the Web forms from ontological constraints, which support the controlled update process of a given ontology, and prefills the generated forms. While IOPE is generic and can be applied to ontologies from a variety of domains, we employ an ontology called OntoSAMSEI [3] for demonstration purposes, whose content helps the domain experts design teaching units for learning skills in simulation-based Medicine. OntoSAMSEI's IOPE GUI is accessible via the following link: http://iope.tabasi.info (in French).

\section{INTERACTIVE ONTOLOGY UPDATE}

Our approach consists of transposing the RDF data and the ontological constraints of a given domain ontology into a GUI named IOPE GUI. It functions as a guidance for domain experts to easily explore the ontology and update it through interactive graphical widgets. The input entered by domain experts through the IOPE 

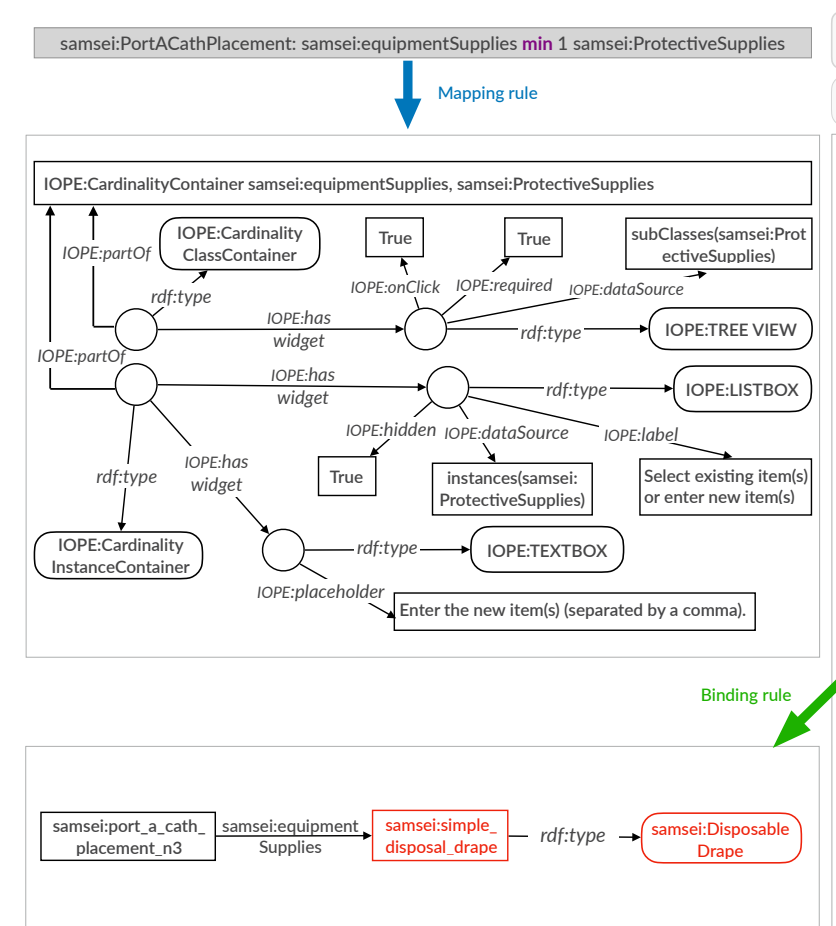

Simulation training session of Port-a-cath placement

Resources

\section{Equipment and supplies: (*)}

Sterile compress (Bandage material) $\left(^{*}\right)$

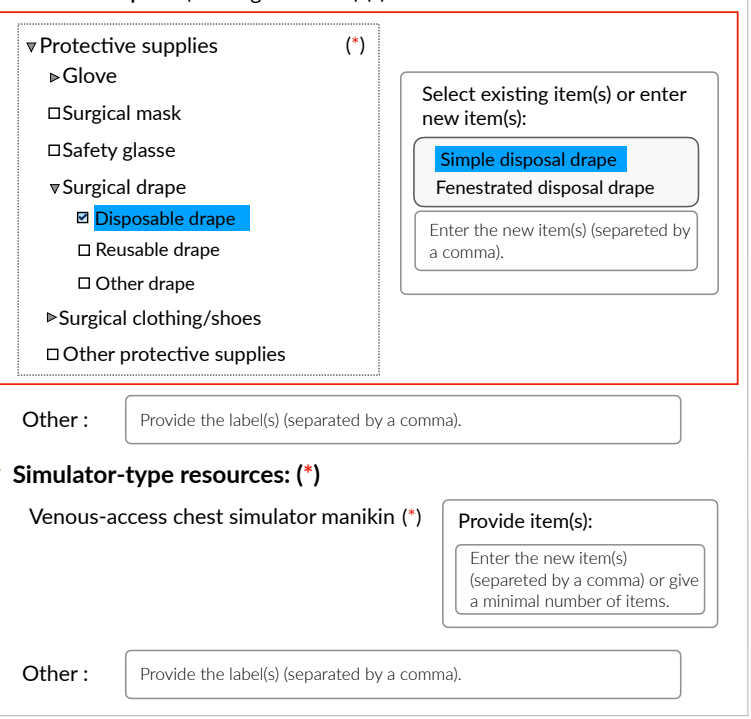

Warning! To save the information entered on this page, you must click on "Save".

Figure 2: An instance of a pre-filled Web page generated by applying the mapping rules to ontological constraints, and the transformation of interactions with the binding rules.

GUI is transformed into RDF triples that must be verified by an ontology engineer before being added effectively in the domain ontology. Figure 1 is an overview of our interactive IOPE system. In the following, we describe the components of IOPE workflow.

Input: A domain ontology is the input for GUI construction. The ontological constraints of the input ontology have been automatically saturated by a reasoning algorithm, detailed in [4].

IOPE GUI: The GUI consists of automatically generated pre-filled Web pages which represent domain ontological constraints. We specify a set of 16 mapping rules to generate pre-filled Web pages [4]. The domain expert is guided using the generated pages, where she interacts with the GUI to explore and update the ontology through interactive graphical widgets. Those interactions must be bound to RDF data corresponding to new instances or new constraints submitted for populating or enriching the domain ontology. We specify a set of 9 binding rules to generate RDF graphs from user entries [4]. The resulting $\mathrm{RDF}$ graphs should be verified by an ontology engineer before adding to the domain ontology.

Output: The output is the updated RDF data and the updated ontological constraints.

Figure 2-right illustrates one of the resulting pre-filled Web pages generated by applying the mapping rules to OntoSAMSEI's ontological constraints, to represent information about the workshop required resources, e.g., equipment and supplies, and simulator-type resources. At the top-left of the figure, an ontological constraint is mentioned in Turtle format ${ }^{1}$, conveying that at least one equipment of type "protective supply" is mandatory for this workshop. Obviously, the Turtle format is difficult to be comprehended by users without OWL/RDFS knowledge. The graph-based result of a mapping rule applied on the constraint is shown in the middle-left part of the figure, whose HTML implementation is highlighted with a red-border square on the right side. The user interactions with the pre-filled Web page are highlighted in blue, where the educator selects a sub-class Disposable Drape from the Protective Supplies hierarchy, and picks the instance Simple disposable drape from the provided list of instances. The interactions are transformed into RDF graphs using the binding rule shown in the bottom-left part of the figure. This transformation results in two RDF triples which declare relations between an instance of the workshop and the selected instance, and between the selected instance and its class.

\section{REFERENCES}

[1] Yixiang Fang, Reynold Cheng, Siqiang Luo, Jiafeng Hu, and Kai Huang. C-Explorer: Browsing communities in large graphs. VLDB, 2017.

[2] Nathalie Henry, Jean-Daniel Fekete, and Michael J. McGuffin. Nodetrix: a hybrid visualization of social networks. TVCG, 2007.

[3] Shadi Baghernezhad-Tabasi, Loic Druette, Fabrice Jouanot, Celine Meurger, and Marie-Christine Rousset. OntoSAMSEI: Interactive ontology engineering for supporting simulation-based training in medicine. In WETICE, 2021.

[4] Shadi Baghernezhad-Tabasi, Loïc Druette, Fabrice Jouanot, Celine Meurger, and Marie-Christine Rousset. IOPE: Interactive ontology population and enrichment guided by ontological constraints. In WISE, 2021.

$\overline{{ }^{1} \text { https://www.w3.org/TR/turtle/ }}$ 